\title{
Solvatochromic parameters for binary mixtures of an ionic liquid with various protic molecular solvents
}

\author{
Mohammad Khodadadi-Moghaddam • \\ Aziz Habibi-Yangjeh · Mohamad Reza Gholami
}

Received: 4 June 2008/ Accepted: 13 June 2008/Published online: 2 September 2008

(c) The Author(s) 2008. This article is published with open access at Springerlink.com

\begin{abstract}
Solvatochromic parameters $\left(E_{T}^{\mathrm{N}}\right.$, normalized polarity parameter; $\pi^{*}$, dipolarity/polarizability; $\beta$, hydrogen-bond acceptor basicity; $\alpha$, hydrogen-bond donor acidity) have been determined for binary mixtures of propan-2-ol, propan-1-ol, ethanol, methanol and water with recently synthesized ionic liquid (IL; 2-hydroxyethylammonium formate) at $25^{\circ} \mathrm{C}$. In all solutions except aqueous solution, $E_{T}^{\mathrm{N}}$ values of the media increase abruptly with the ILs mole fraction and then increase gradually to the value of pure IL. A synergistic behavior is observed for the $\alpha$ parameter in all solutions. The behavior of $\pi^{*}$ and $\beta$ are nearly ideal for all solutions except for solutions of methanol with the IL. The applicability of nearly ideal combined binary solvent/Redlich-Kister equation was proved for the correlation of various solvatochromic parameters with solvent composition. The correlation between the calculated and the experimental values of various parameters was in accordance with this model. Solute-solvent and solvent-solvent interactions were applied to interpret the results.
\end{abstract}

Keywords Solvatochromic parameters - Ionic liquid . Dipolarity/polarizability

M. Khodadadi-Moghaddam · M. R. Gholami ( $₫)$ Department of Chemistry, Sharif University of Technology, P.O. Box 11365-9516, Tehran, Iran e-mail: Gholami@sharif.edu

A. Habibi-Yangjeh

Department of Chemistry, Faculty of Science,

University of Mohaghegh Ardabili, P.O. Box 179, Ardabil, Iran

\section{Introduction}

One of the biggest problems in the chemical industry is to deal with the fact that all chemical plants rely heavily on toxic, hazardous, and flammable organic solvents. Roomtemperature ionic liquids (RTILs) with no measurable vapor pressure can be a good replacement for organic solvents. RTILs are organic salts composed of anions and cations that are in the liquid state at ambient conditions. RTILs have properties that make their application in chemical systems attractive [1-4]. These compounds have been used as novel solvent systems for organic synthesis [5-7], liquid-liquid extraction [8-10], electrochemical studies [11], and as ultra-low-volatility liquid matrixes for matrix-assisted laser desorption/ionization (MALDI) mass spectrometry [12]. Some RTILs are nonpolar organic solvents and immiscible with water. They have good thermal stability (over $300{ }^{\circ} \mathrm{C}$ ) and yet possess negligible vapor pressure, making them "green" solvents with regard to their effect in reducing environmental levels of volatile organic carbons (VOCs). Most ILs are said to have similar polarities, close to those of short-chain alcohols [12-14], and some of them have polarities close to water or acetone [15]. However, their solvent properties can differ considerably from one another as well as from traditional molecular solvents.

To expand the utility of RTILs and improve their physicochemical properties, recently researchers have been focusing on RTIL-based mixed solvent systems. One area of interest is when RTILs are combined with other solvents to tailor the physicochemical properties of a particular RTIL in a favorable fashion [16-19]. To increase the efficiency of a process (e.g. separation, extraction, synthesis, etc.), a solvent or solvent mixture is tuned by adding cosolvents. It is beneficial in many ways to understand how 
added cosolvents (or impurities) affect the physicochemical properties of RTILs.

Studying solute-solvent and solvent-solvent interactions using solvatochromic probes is both simple and convenient, because the transition energy of the indicator depends on the solvating sphere composition and properties [20-24]. Solvatochromic probe studies offer direct information on solvent properties, such as polarities, dipolarity/polarizability and hydrogen-bond donating/accepting capabilities. The study of physicochemical properties that depend on solute-solvent is much more complex in mixed solvent systems than in pure solvents [20]. The solute can be preferentially solvated by any of the solvents present in the mixture, and solvent-solvent interactions can also strongly affect solute-solvent interactions.

In this work, solvatochromic parameters $\left(E_{T}^{\mathrm{N}}\right.$, normalized polarity parameter; $\pi^{*}$, dipolarity/polarizability; $\beta$, hydrogen-bond acceptor basicity; $\alpha$, hydrogen-bond donor acidity) have been determined for binary mixtures of propan-2-ol, propan-1-ol, ethanol, methanol, and water with a recently synthesized IL (2-hydroxyethylammonium formate) at $25{ }^{\circ} \mathrm{C}$ over the whole mole fraction. Solutesolvent and solvent-solvent interactions have been applied for interpreting the parameters.

\section{Results and discussion}

The values of solvatochromic parameters $\left(E_{T}^{\mathrm{N}}, \pi^{*}, \beta\right.$, and $\left.\alpha\right)$ have been determined from the corresponding chemical probe wave numbers for binary mixtures of propan-2-ol, propan-1-ol, ethanol, methanol, and water with recently synthesized IL (2-hydroxyethylammonium formate) at $25{ }^{\circ} \mathrm{C}$. In order to demonstrate the changes in the IL solvatochromic parameters, addition of the cosolvent, the plots of $E_{T}^{\mathrm{N}}, \pi^{*}, \alpha$, and $\beta$ parameters versus cosolvent mole fractions are presented in Figs. 1, 2, 3, 4 and 5.

\section{The propan-2-ol/2-hydroxyethylammonium formate system}

The $\pi^{*}$ parameter is derived from the variation of energy corresponding to the dye maximum absorption, which is induced by the local electric field generated by the solvent. It is not surprising that $\pi^{*}$ is greatly affected by increasing dye-ion solute-solvent interactions when the mole fraction of the IL increases. The hydrogen-bond basicity of RTILs is mainly dominated by the nature of the anion. The anion of 2-hydroxyethylammonium formate is known to have a compact structure possessing much weaker bacisity in comparison to propan-2-ol. As illustrated in Fig. 1, the $\pi^{*}$ values produce a negative deviation, while the $\beta$ parameter produces a small positive deviation from ideality. Ideal

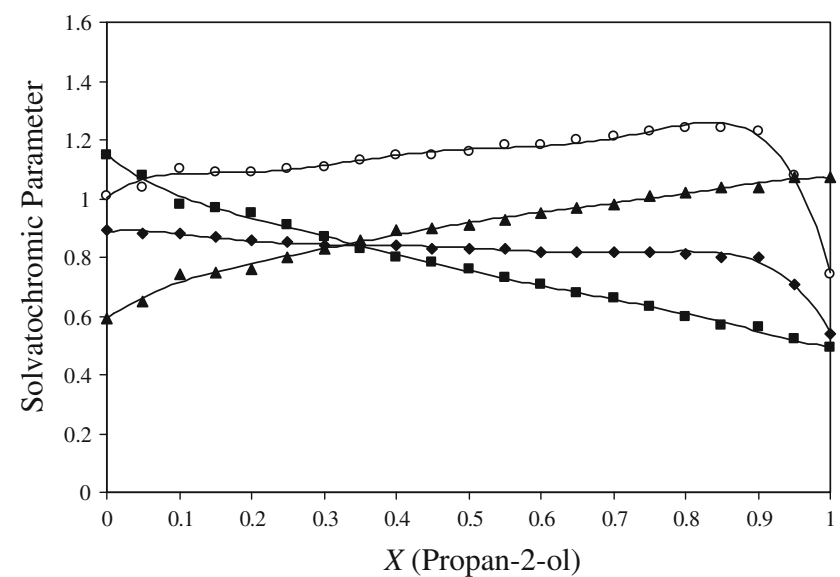

Fig. 1 Solvatochromic parameters for propan-2-ol/2-hydroxyethylammonium formate system $\left(E_{T}^{\mathrm{N}}\right.$, diamonds; $\pi^{*}$, square; $\alpha$, circle; $\beta$, triangle)

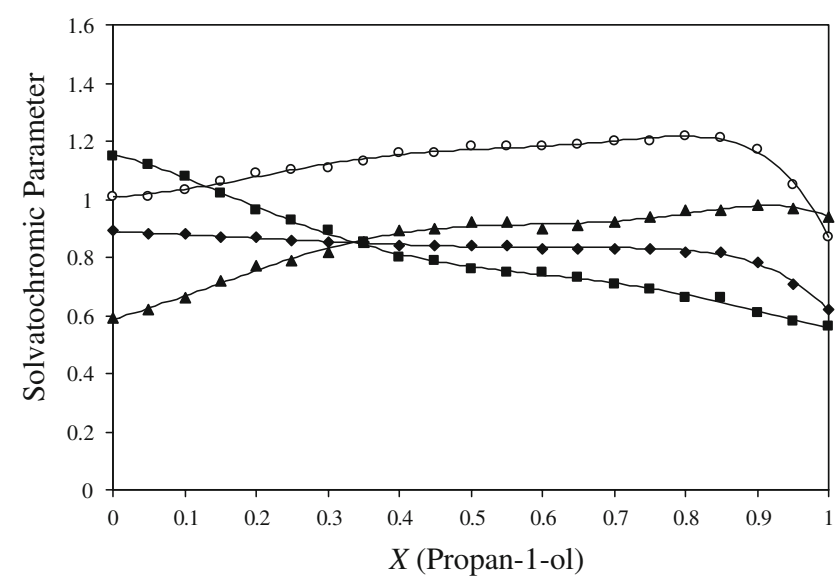

Fig. 2 Solvatochromic parameters for propan-1-ol/2-hydroxyethylammonium formate system $\left(E_{T}^{\mathrm{N}}\right.$, diamonds; $\pi^{*}$, square; $\alpha$, circle; $\beta$, triangle)

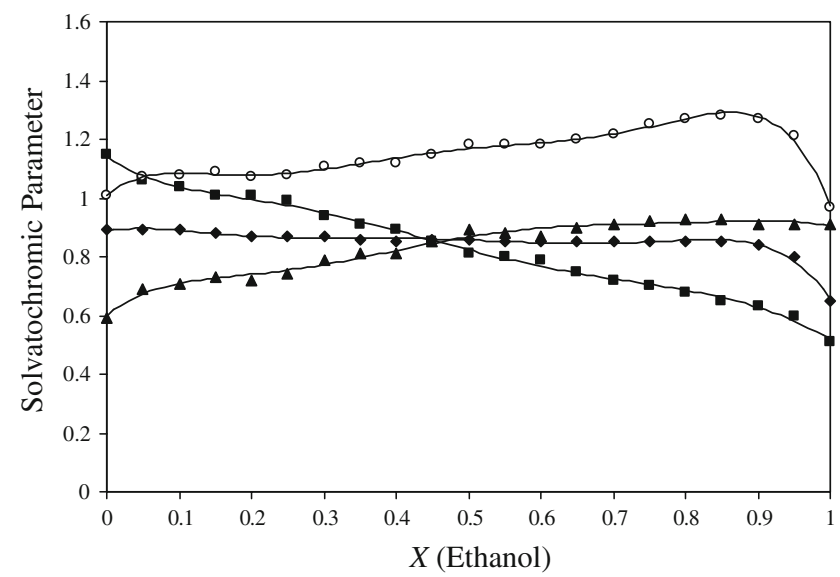

Fig. 3 Solvatochromic parameters for ethanol/2-hydroxyethylammonium formate system $\left(E_{T}^{\mathrm{N}}\right.$, diamonds; $\pi^{*}$, square; $\alpha$, circle; $\beta$, triangle) 


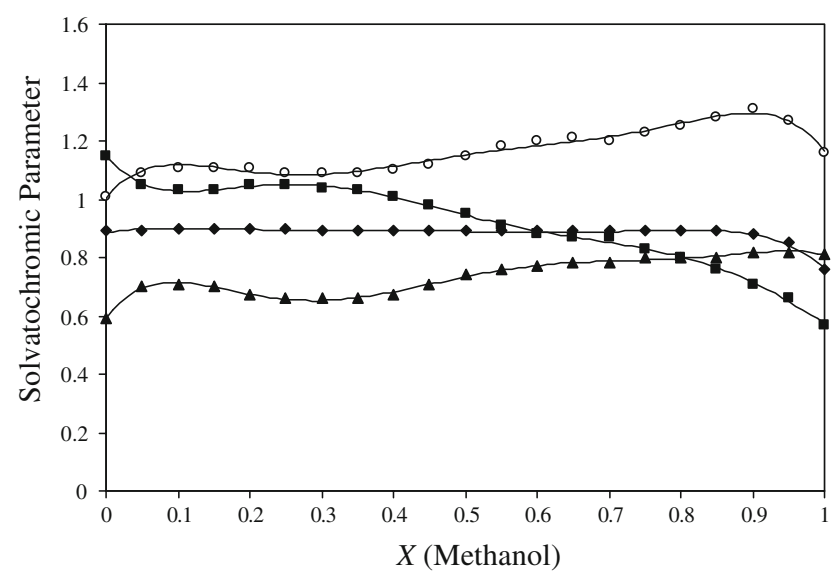

Fig. 4 Solvatochromic parameters for methanol/2-hydroxyethylammonium formate system $\left(E_{T}^{\mathrm{N}}\right.$, diamonds; $\pi^{*}$, square; $\alpha$, circle; $\beta$, triangle)

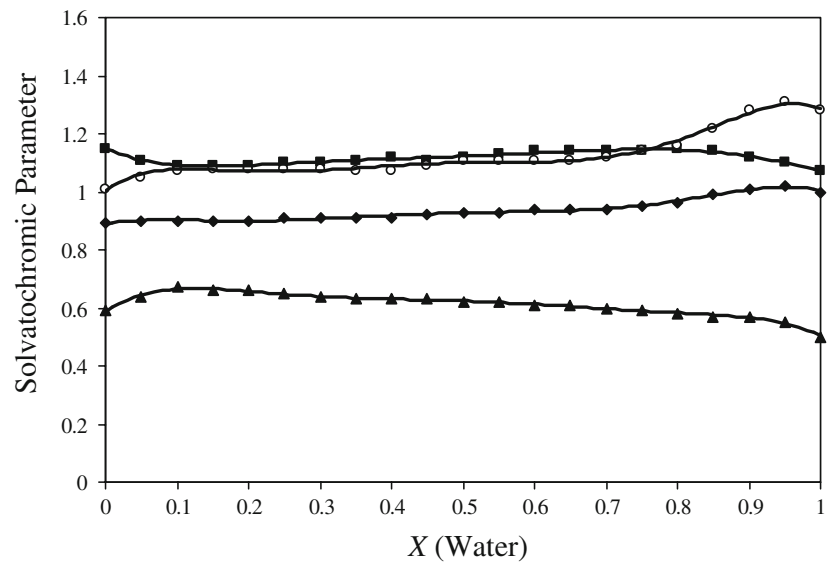

Fig. 5 Solvatochromic parameters for water/2-hydroxyethylammonium formate system $\left(E_{T}^{\mathrm{N}}\right.$, diamonds; $\pi^{*}$, square; $\alpha$, circle $; \beta$, triangle)

mixtures show a linear relationship among the solvatochromic parameter, the solvent composition, and the probe that are equally solvated by the constituents of mixtures [24].

The $E_{T}^{\mathrm{N}}$ and $\alpha$ are not linearly dependent on the mole fraction of the cosolvent. The reason for this nonlinear behavior is "preferential solvation" of the probe by one component of the binary mixture. Preferential solvation arises whenever the bulk mole fraction solvent composition is different from the solvation microsphere [25]. In principle, this phenomenon includes the contribution of specific (e.g., H-bonding) and non-specific probe-solvent interactions [26-28]. The $\alpha$ parameter of the RTILs is largely affected by the nature of the cation, but there is also a small anion effect. By adding small quantities of the IL, the $\alpha$ parameter shows synergistic behavior that can be attributed to hydrogen bond interactions between the IL and propan-2ol. This complex is a more polar and a better hydrogen-bond donor than the constituents of the mixture, because the IL is polar, and protic solvent is able to act both as a donor and an acceptor solvent $\left(E_{T}^{\mathrm{N}}=0.89, \pi^{*}=1.15, \alpha=1.01\right.$ and $\beta=0.59$ ). Figure 1 shows a region with large increases in $E_{T}^{\mathrm{N}}$ at low IL concentrations for a relatively small increase in cosolvent concentration. The betaine dye has a highly dipolar ground state in comparison to its excited state and therefore exhibits a significant permanent dipole moment, a large polarizable $\pi$ electron system, a substantial negative charge on the phenoxide oxygen, and a positive charge on the pyridinium nitrogen. The strong negative charge on the phenoxide oxygen of betaine dye in the electronic ground state can acquire additional solvent stabilization by hydrogen-bonding interactions with the IL, which increases $E_{T}^{\mathrm{N}}$ values, that is, the betaine dye is much more preferentially solvated by the IL than the molecular solvent. A second region is also observed in which $E_{T}^{\mathrm{N}}$ varies smoothly by the nonspecific solvation effects due to the complex formation of betaine-IL complex.

\section{The propan-1-ol/2-hydroxyethylammonium formate system}

Similar to the propan-2-ol/2-hydroxyethylammonium formate system, the $\pi^{*}$ and $\beta$ parameters vary almost ideally with negative deviation, while a weak synergistic effect on the $\beta$ value is observed at low IL concentrations (Fig. 2). Addition of small quantities of the IL causes the $\alpha$ and $E_{T}^{\mathrm{N}}$ parameters to increase abruptly and then decrease smoothly to the value of the pure IL. The $E_{T}^{\mathrm{N}}$ value changes gradually with the mole fraction of propan-1-ol from 0 to 0.9 and falls rapidly to 0.62 the value for pure propan-1-ol. Similar to the propan-2-ol/2-hydroxyethylammonium formate system, the synergistic behavior was observed in $\alpha$ curve for the IL mole fraction of $0.2(\alpha=1.22)$.

\section{The ethanol/2-hydroxyethylammonium formate system}

There is no distinct difference between the ethanol/2hydroxyethylammonium formate system and the systems described previously. Similar to propan-2-ol/IL and propan-1-ol/IL systems, there are no synergistic effects in $\pi^{*}$, $\beta$, and $E_{T}^{\mathrm{N}}$ curves (Fig. 3). By adding small quantities of the $\mathrm{IL}$, the $E_{T}^{\mathrm{N}}$ parameter increases abruptly and then remains nearly constant at the value close to the one for pure IL. The $\pi^{*}$ values fall continuously from 1.15 to 0.51 , and the $\beta$ values increase from 0.59 to 0.91 with nearly ideal behavior. In addition, the synergistic effect appeared in $\alpha$ curve with the maximum value of 1.28 at $X_{\mathrm{IL}}=0.15$.

\section{The methanol/2-hydroxyethylammonium formate} system

The behavior of $\alpha$ and $E_{T}{ }^{\mathrm{N}}$ parameters are similar to the observed shapes for mixtures of the IL with other alcohols. 
The values for $\pi^{*}$ and $\beta$ deviate from ideality in this mixture (Fig. 4).

\section{The water/2-hydroxyethylammonium formate system}

Solvatochromic properties of the water/IL system are different from alcoholic systems (Fig. 5). In the water/IL system, a very small synergism is found for $\beta, \alpha$, and $E_{T}^{\mathrm{N}}$ parameters. Maximum values of these parameters were obtained at $X_{\mathrm{IL}}=0.90$ for $\beta$ and $X_{\mathrm{IL}}=0.05$ for $\alpha$ and $E_{T}{ }^{\mathrm{N}}$. The synergistic behavior indicates that a hydrogen-bonded complex between water and IL has been formed. The IL is a hydrogen-bond donor, and hydrogen-bond acceptor solvent can form HBD and HBA interactions with water. The $\pi^{*}$ and $\beta$ parameters show a positive deviation from nearly ideal behavior (Fig. 5).

\section{The excess solvatochromic parameters for molecular solvent/IL binary systems}

The solvatochromic parameters can be calculated from Eq. 1:

$$
\Delta Y=Y_{\text {mixture }}-\left(x_{\mathrm{IL}} Y_{\mathrm{IL}}^{0}+x_{\text {Solv }} Y_{\text {solv }}^{0}\right)
$$

where $\Delta Y, Y_{\text {mixture }}, Y_{\mathrm{IL}}^{0}, Y_{\mathrm{solv}}^{0}, x_{\mathrm{IL}}$, and $x_{\text {solv }}$ are the excess solvatochromic parameter, mixture solvatochromic parameter, solvatochromic parameters of IL, molecular cosolvent, the molar ratio of the IL, and the molecular solvent, respectively.

$\Delta \pi^{*}$ values are negative for propan-2-ol/IL and propan1-ol/IL with a minimum at the IL rich region and in the middle of mole fractions, respectively. Its values are negative in the IL-rich region and positive in the cosolvent-rich region for ethanol, methanol, and water cosolvents. Reinforcement of the cosolvent structure by addition of small IL amounts produces an increase in polarity-polarizability of the solvent mixture in the cosolvent rich region.

$\Delta \beta$ was positive for all binary mixtures except for methanol, which was zero or slightly negative in some molar ratios (Fig. 6). In all mixtures, $\Delta \beta$ increases slightly with increasing IL, which reveals that the hydrogen bond basicity increases with the IL content.

Positive $\Delta \beta$ values indicate preferential salvation of the probe by the more polar component, while negative values show preferential salvation by the less polar component [29]; hence, these indicators are preferentially solvated by the IL in all mixtures.

\section{Theoretical calculations}

The basis of these calculations has been explained in our previous work [30]. The "excess solvatochromic parameters," $\mathrm{SP}^{\mathrm{E}}\left(\mathrm{SP}\right.$ is $\pi^{*}, \alpha, \beta$, or $E_{T}^{\mathrm{N}}$ ), can be calculated
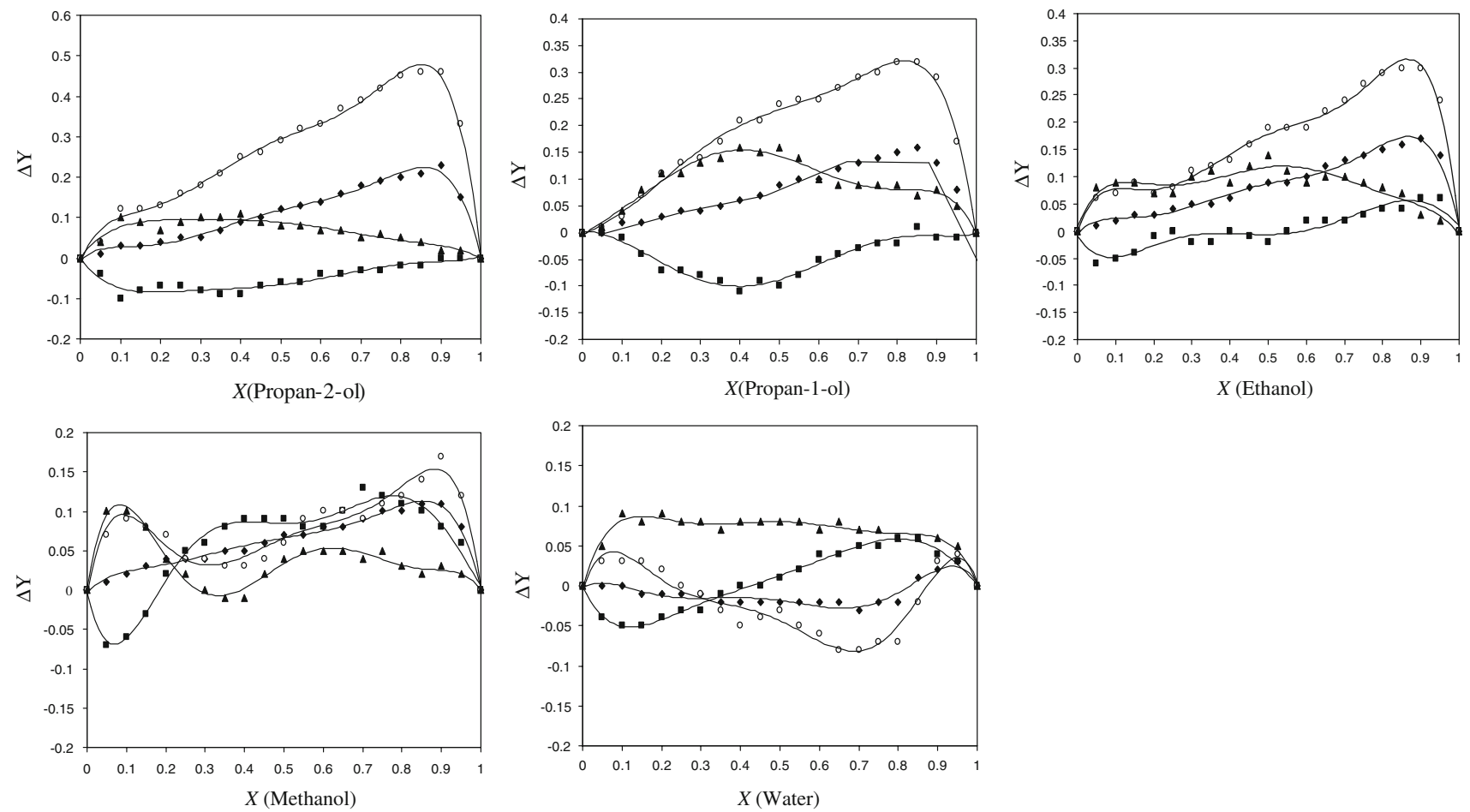

Fig. 6 Excess solvatochromic parameters $(\Delta Y)$ for molecular solvent/2-hydroxyethylammonium formate system $\left(E_{T}{ }^{\mathrm{N}}\right.$, diamonds; $\pi^{*}$, square; $\alpha$, circle $; \beta$, triangle) 
according to Eq. 2 in which the variation of any property is related to pure and mixed solvent properties:

$\mathrm{SP}^{\mathrm{E}}=\mathrm{SP}_{\mathrm{m}}-\sum_{i=1}^{2} x_{i} \mathrm{SP}_{i}$

where $\mathrm{SP}_{\mathrm{m}}$ and $\mathrm{SP}_{i}$ are the corresponding parameters for the solvent mixture and the pure solvents, respectively, and $x_{i}$ is the mole fraction of one solvent. The CNIBS/R-K model provides a simple method to correlate and/or predict the excess molar properties of a solute dissolved in a binary or ternary solvent mixture. This is given in terms of a weighted mole fraction average of solute properties in the pure solvents and contributions of solute-solvent and solvent-solvent interactions [31-36]. The solvatochromic parameters $(S P)$ in a binary solvent mixture at a constant temperature can be expressed as in Eq. 3:

$\mathrm{SP}_{\mathrm{m}}=x_{1} \mathrm{SP}_{1}^{0}+x_{2} \mathrm{SP}_{2}^{0}+x_{1} x_{2} \sum_{j=0}^{k} A_{j}\left(x_{1}-x_{2}\right)^{j}$

where $\mathrm{SP}_{\mathrm{m}}, \mathrm{SP}_{1}^{0}$, and $\mathrm{SP}_{2}^{0}$ are solvatochromic parameters determined in mixed and pure solvents 1 and 2, respectively, and $x_{1}$ and $x_{2}$ are the mole fractions of the binary solvent mixture. $A_{j}$ and $j$ are the equation coefficients and the degree of the polynomial expansion. The numerical values of $j$ can be varied between 0 and 3 to find an accurate mathematical representation of the experimental data. A partial least-squares regression (PLSR) method was used to fit the polynomials to the experimental data. A cross-validation method has been applied to predict any of the parameters. This method is a practical and reliable way to test the predictive significance when few data are available [37]. In Fig. 7, the predicted values of $\mathrm{SP}\left(E_{T}^{\mathrm{N}}, \beta, \pi^{*}\right.$, and $\left.\alpha\right)$ obtained by the crossvalidation method using Eqs. 2 and 3 for various binary solvent mixtures are plotted versus the corresponding

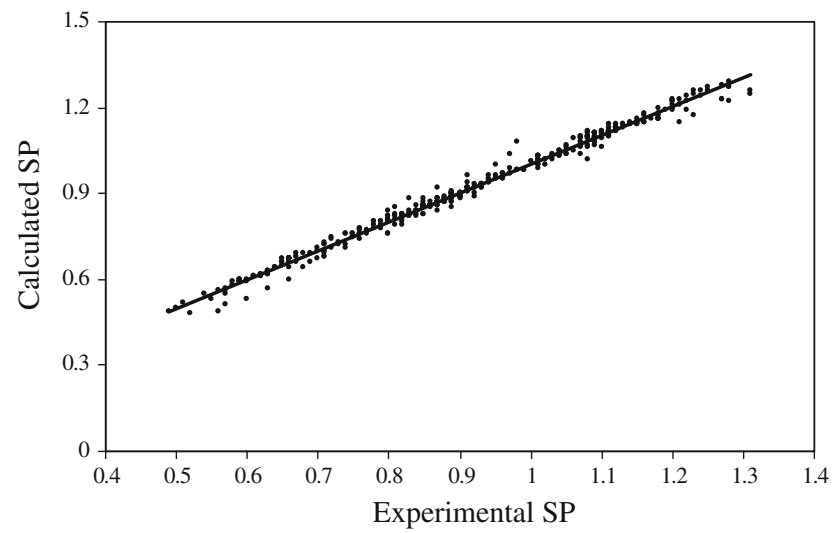

Fig. 7 Predicted values of solvatochromic parameters from the correlation equations versus its experimental values for binary mixtures of 2-hydroxyethylammonium formate with water, methanol, ethanol, propan-1-ol, and propan-2-ol experimental values. Equation 4 is obtained for this correlation, and it is clear that the correlation is reasonable.

$$
\begin{array}{r}
\mathrm{SP}_{\mathrm{m}}^{\text {calc }}=1.0042( \pm 0.005) \mathrm{SP}_{\mathrm{m}}^{\exp }-0.0035( \pm 0.005) \\
n=420, \quad R^{2}=0.9903, \quad \sigma=0.01858
\end{array}
$$

The standard deviation, $\sigma$, was obtained from Eq. 5:

$\sigma=\left(\frac{\sum_{i=1}^{n}\left(\mathrm{SP}_{\mathrm{i}}^{\exp }-\mathrm{SP}_{\mathrm{i}}^{\text {calc }}\right)^{2}}{n}\right)^{1 / 2}$

where $n, \mathrm{SP}_{i}^{\exp }$, and $\mathrm{SP}_{i}^{\text {calc }}$ are the number of the experimental data points, the experimental, and calculated solvatochromic parameter in the binary solvent mixtures, respectively.

The model shows a strong correlation between predicted and experimentally measured values. Proportional and systematic errors were not observed. Therefore, the CNIBS/R-K model is reasonable with high confidence for prediction of the solvatochromic parameters in binary solvent mixtures of 2-hydroxyethylammonium formate with propan-2-ol, propan-1-ol, ethanol, methanol, and water.

This article does not experimentally include the solvatochromic evaluation of Lewis acid and base concepts. The solvatochromic technique to determine the donor number of anions in solution using the solvatochromic dye $[\mathrm{Cu}(\mathrm{acac})(\mathrm{tmen})] \mathrm{BPh}_{4}$ (acac, acetylacetonate; tmen, $N, N, N^{\prime}, N^{\prime}$-tetramethylethylenediamine) has been described in detail in the literature [38]. The ability of an anion to coordinate to a metal center is determined in part by the competition it receives from the solvent (and other bases present in solution). When the donor strength of the solvent is higher than that of the anion, the solvent preferably coordinates to the copper complex, but, on the other hand, a solvent exhibiting strong acceptor property will compete with the copper complex for solvation of the anion.

\section{Experimental}

2,6-Diphenyl-4-(2,4,6-triphenyl-1-pyridino)-phenolate, the indicator solute for the $E_{T}(30)$ scale, was purchased from Aldrich chemical company. 4-Nitroanisole and 4-nitroaniline were purchased from Merck. All the probes were of the highest purity available and were used as received. Methanol and ethanol (Merck), propan-1-ol (Riedel de Haen) propan-2-ol (Fluka) ethanolamine, and formic acid (Riedel de Haen) were purified according to the literature [25]. Double-distilled water was used as cosolvent. Mixed solvents were prepared by carefully mixing the components by weight. Spectral measurements were taken by a Cinta 40 spectrophotometer. Temperature was controlled at $25 \pm 0.1^{\circ} \mathrm{C}$ by circulating water through a NESLAB 
thermostat. Maximum absorption was determined from the first derivative of wavelength scan. To check the reproducibility, the position of the maximum absorption in a particular solvent mixture was repeated several times. The precision of replicated measurements was $\pm 1 \mathrm{~nm}$. The concentrations of the probes in the solutions were $10^{-5}$, $5 \times 10^{-6}$, and $10^{-4} \mathrm{M}$ for 4-nitroanisole, 4-nitroaniline, and Reichardt's dye, respectively. The $E_{T}(30), \pi^{*}, \beta$, and $\alpha$ parameters were calculated from the maximum absorption wavelength according to the procedure reported elsewhere [21]. Reichardt's dye is insoluble in water. Therefore, $E_{T}(30)$ could not be measured in pure water, and hence the literature value was used [22]. The IL was prepared and characterized as described in the literature [23].

Acknowledgments The authors are grateful to Sharif University of Technology for financial support.

Open Access This article is distributed under the terms of the Creative Commons Attribution Noncommercial License which permits any noncommercial use, distribution, and reproduction in any medium, provided the original author(s) and source are credited.

\section{References}

1. Armstrong DW, He L, Liu YS (1999) Anal Chem 71:3873

2. Berthod A, He L, Armstrong DW (2001) Chromatographi A 53:63

3. Wilkes JS, Zaworotko MJ (1992) J Chem Soc Chem Commun 965

4. Adams CJ, Earle MJ, Roberts G, Seddon KR (1998) Chem Commun 2097

5. Earle MJ, McCormac PB, Seddon KR (1998) Chem Commun 2245

6. Dyson PJ, Ellis DJ, Parker DG, Welton T (1999) Chem Commun 25

7. Leadbeater NE, Torenius HM (2002) J Org Chem 67:3145

8. Mann BE, Guzman MH (2002) Inorg Chim Acta 330:143

9. Huddleston JG, Willauer HD, Swatloski RP, Visser AE, Rogers RD (1998) Chem Commun 1765

10. Dai S, Ju YH, Barnes CE (1999) J Chem Soc Dalton Trans 1201
11. Dickinson VE, Willaims ME, Hendrickson SM, Masui H, Murray RW (1999) J Am Chem Soc 121:613

12. Armstrong DW, Zhang LK, He L, Gross ML (2001) Anal Chem 73:3679

13. Muldoon MJ, Gordon CM, Dunkin IR (2001) J Chem Soc Perkin Trans 2:433

14. Carmichael AJ, Seddon KR (2000) J Phys Org Chem 13:591

15. Reichardt C (2005) Green Chem 7:339

16. Najdanovic-Visak V, Esperanca JMSS, Rebelo LPN, da Ponte MN, Guedes HJR, Seddon KR, Szydlowski J (2002) Phys Chem Chem Phys 4:1701

17. Swatloski RP, Visser AE, Reichert WM, Broker GA, Farina LM, Holbrey JD, Rogers RD (2001) Chem Commun 2070

18. Swatloski RP, Visser AE, Reichert WM, Broker GA, Farina LM, Holbrey JD, Rogers RD (2002) Green Chem 4:81

19. Seddon KR, Stark A, Torres MJ (2000) Pure Appl Chem 72:2275

20. Roses M, Rafols C, Ortega J, Bosch E (1995) J Chem Soc Perkin Trans 21607

21. Garcia B, Aparicio S, Alcalde R, Ruiz R, Davola MJ, Leal JM (2004) J Phys Chem B 108:3024

22. Herodes K, Leito I, Koppel I, Roses M (1999) J Phys Org Chem 12:109

23. Biack N (2005) J Mol Liq 116:15

24. Mancini PM, Fortunato GG, Vottero LR (2004) Phys Chem Liq 42:625

25. Perrin DD, Armarego WLF (1988) Purification of laboratory chemicals, 3rd edn. Pergamon Press, New York

26. Antonious MS, Tada EB, El Seoud OA (2005) J Phys Org Chem 15:1

27. Fletcher KA, Pandey S (2003) J Phys Chem B 107:13532

28. Fletcher KA, Pandey S (2002) Appl Spectrosc 56:266

29. Kemmel M, Pirila P (2000) J Solution Chem 29:87

30. Harifi-Mood AR, Habibi-Yangjeh A, Gholami MR (2006) J Phys Chem B 110:7073

31. Hernandez CE, Coym KS, Roy LE, Powell JR, Acree WE (1998) J Chem Thermodyn 30:37

32. Al-Sharrah GK, Ali SH, Fahim MA (2002) Fluid Phase Equilib 193:191

33. Iloukhani H, Rezaei-Sameti M, Zarei HA (2005) Thermochim Acta 438:9

34. Wang J, Wu J (2005) J Chem Eng Data 50:980

35. Kadam UB, Hiray AP, Sawant AB, Hasan M (2006) J Chem Eng Data 51:60

36. Habibi-Yangjeh A (2004) Bull Korean Chem Soc 25:1165

37. Reichardt C (1994) Chem Rev 94:2319

38. Linert W, Jameson RF, Taha A (1993) J Chem Soc Dalton Trans 3181 